\title{
КОНСПЕКТ УРОКА КАК ТЕСТОВОЕ ЗАДАНИЕ ОТКРЫТОГО ТИПА СО СВОБОДНО КОНСТРУИРУЕМЫМ ОТВЕТОМ
}

\author{
Д-р Юлия Сутугинене \\ Петербургский государственный университет путей сообщения \\ императора Александра I (Санкт-Петербург, Россия)
}

\begin{abstract}
Аннотация. В настоящей статье автор теоретически обосновывает и практически доказывает иелесообразность использования тестовых заданий открытого типа со свободно конструируемым ответом при проверке квалификационной пригодности бакалавров по специальности РКИ в вузах Литвы и России. В роли такого задания выступает письменно изложенный студентами конспект урока, объективно оценить который помогает разработанная стандартизированная и апробированная в ходе многочисленных экспериментов измерительная таблица, в которой экспертным методом определены подлежащие обязательному оцениванию характеристики, а также обоснованы числовые показали таблицы, что и позволяет расиенивать такое задание как тестовое.
\end{abstract}

Ключевые слова: тестовые задания открытой формы, тестовые задания открытого типа со свободно конструируемым ответом, педагогические измерения, контроль, конспект урока, РКИ.

\section{Вводные замечания}

С момента введения ЕГЭ в систему контроля знаний учащихся вопрос использования тестов закрытого типа всё чаще становится предметом незатихающих научных и околонаучных споров, а также неослабевающего внимания со стороны широкой общественности. Вместе с тем применение тестов открытого типа остаётся вне поля зрения как исследователей-тестологов, так и педагогов-практиков. Таким образом, проблема, которая поднимается в данной статье, заключается в том, что использование тестовых заданий открытого типа со свободно конструируемым ответом в процессе контроля бакалавров, будущих учителей русского языка как иностранного (РКИ), незаслуженно игнорируется современным педагогическим сообществом. В этой связи объектом исследования настоящей статьи служит контроль квалификационной пригодности будущих учителей РКИ, обучающихся в вузах Литвы и России, 
проводимый при помощии тестового задания открытого типа, в роли которого выступает создание студентами конспекта урока.

Цель работы - теоретически обосновать и экспериментально доказать необходимость разработки тестового задания со свободно конструируемым ответом и целесообразность его включения в контроль для объективного измерения квалификационной пригодности выпускников по специальности РКИ.

В соответствии с целью были поставлены следующие задачи:

1. Доказать правомерность использования в педагогическом контроле тестовых заданий открытого типа со свободно конструируемым ответом.

2. Разработать измерительную таблицу для объективного оценивания письменной формы контроля как тестового задания открытого типа со свободно конструируемым ответом (конспекта урока).

3. Апробировать разаботанную измерительную таблицу.

В целях реализации задач исследования был использован комплекс методов, отражающих единство теоретического и эмпирического методов познания: методы теоретического анализа источников; опросные методы; наблюдение; анализ продуктов педагогической деятельности, включая оценку независимых экспертов (метод экспертных оценок); проведение экспериментов; тестирование.

\section{Основная часть}

В педагогической диагностике под тестированием понимаются методы, с помощью которых результаты учебного процесса могут быть измерены (максимально сопоставимо, надёжно и валидно), обработаны и интерпретированы с целью использования результатов измерений в педагогической практике. Максимальная сопоставимость полученного ответа с эталоном правильного ответа на задание обеспечивает тестовому контролю научно-обоснованную стандартизацию, которую можно определить как процедуру создания интерпретационной базы (измерительной таблицы). Следовательно, среди всех существующих форм контроля, именно педагогические тесты дают наиболее объективную информацию о качестве обученности испытуемых.

Современные тестологи (Аванесов, 2006; Балыхина, 2006: 86; Кирейцева, 2013: 51; Лазарева, 2011: 16; Переверзев, 2003: 50, и др.), наряду с другими формами тестовых заданий, выделяют два типа заданий открытой формы: задания со свободно конструируемым ответом и задания на дополнение.

В заданиях на дополнение испытуемые должны самостоятельно давать ответы на вопросы, при этом, в отличие от выполнения заданий со свободно конструируемым ответом, их возможности лимитированы. Такие ограничения обеспечивают объективность оценивания результата выполнения задания, а формулировка ответа должна давать возможность однозначного оценивания. Приведём пример задания на дополнение. 
Вместо пропуска впишите только одно слово:

Раздел грамматики, изучающий системы формоизменения слов и правил их образования, называется

Очевидно, что правильным ответом будет служить только вписанное слово «Морфология». При этом все другие ответы (например, «Синтаксис», «Словообразование» и проч.) будут являться ошибочными.

Несмотря на бесспорную объективность задания на дополнение, с нашей точки зрения именно тестовое задание открытого типа со свободно конструируемым ответом в полной мере демонстрирует самостоятельную работу студента, его творческий подход к педагогической деятельности, при этом исключает возможность списывания, использования заранее приготовленного материала и проч., что позволяет проверить умения студентов осознанно и творчески применять полученные знания на практике. Такие задания предполагают продуцируемую (устную или письменную) речь испытуемых по сути задания. При этом на ответы не накладывается ограничения.

Представим пример тестового задания открытого типа со свободно конструируемым ответом.

Проанализируйте ситуацию и предложите свой вариант педагогических действий.

52. Если ваш ученик - экстраверт, основными формами работы на ваших занятиях будут .... .

Получив такое задание, испытуемый должен вспомнить, что по типу общения люди условно могут быть разделены на интровертов и экстравертов и необходимо учитывать психологические различия между такими учащимися. Соответственно, правильный ответ на данное задание будет описывать активные формы работы на занятии. Задача испытуемого - творчески и правильно описать свою предполагаемую работу. В случае же, если ответ будет содержать преобладание перечисления таких форм работы с экстравертом, как чтение, выполнение письменных упражнений и проч., задание считается выполненным неверно. Проверка данного задания, как и любого тестового задания открытой формы, осуществляется по составленной и апробированной в ходе эмпирической проверки измерительной таблице, которая содержит все правильные ответы или подробные критерии их оценивания.

Самим учащимся задания открытой формы кажутся более трудными, поскольку в них исключается догадка. Действительно, легче выбрать правильный ответ, иногда основываясь не столько на знаниях, сколько на интуиции, чем самому его сформулировать. Однако именно это свойство делает открытые задания исключительно привлекательными для педагогов.

Перечислим преимущества заданий со свободно конструируемым ответом:

- легко разрабатываются; 
- интересны и разнообразны в содержательном плане;

- позволяют испытуемым продемонстрировать способности выразить свои мысли;

- стимулируют к учебе;

- требуют воспроизведения ответа по памяти;

- исключают угадывание при выполнении задания.

Впрочем, несправедливым было бы не указать и существующие недостатки заданий такого типа:

- задания нетехнологичны (не поддаются автоматической проверке, требуют определённого времени на проверку);

- требуют большего времени на выполнение, поэтому позволяют проверить меньшее содержание, потенциально имеют более низкую валидность, чем задания закрытого типа;

- при их проверке сложно полностью избежать субъективности со стороны проверяющего, а интерпретация результатов значительно затруднена.

Отчасти, решению этих проблем и посвящена настоящая статья, ведь именно перечисленные недостатки и рождают недоверие к этому типу заданий. Примечательно, что К. Ингенкамп в своём труде «Педагогическая диагностика» (1991: 240) указывает на интересную полемику в педагогическом обществе: учёные спорят, измеряют ли эти задания, связанные с «производством» ответа, те же признаки, что и «закрытые задания», предлагающие выбор ответа из серии предложенных. «Отношения преподавателей к заданиям, предполагающим выбор ответа, чаще скептическое, вплоть до отрицательного», тут же приводится следующее мнение: «Можно с уверенностью говорить о том, что новые типы тестов обладают, по меньшей мере, той же валидностью, что и традиционные формы проверки» (Haristan, 1971: 324). «Результаты исследований не дают никаких оснований полагать, будто задания с выбором ответа измеряют нечто иное, чем задания со свободным ответом» (Choppin и др., 1969). Другие исследователи настаивают на том, что задания с выбором ответа требуют от учащихся лишь узнавания того материала, который был выучен ими, будто он рассчитан только на знание изолированных, не связанных между собой фактов, будто с его помощью нельзя проверить понимания взаимосвязей и уж абсолютно невозможно определить индивидуальную позицию тестируемого, будто бы этот тип заданий ориентирует учащихся на поверхностное овладение знаниями. Разделяя точку зрения К. Ингенкампа, мы полагаем, что объективное тестирование способно измерять те же признаки (способности, успеваемость), что и большинство так называемых традиционных форм проверки. Более того, если речь идёт о структурировании учебного материала, поисках взаимосвязи между фактами или о новом использовании выученного материала, т.е. о том, что якобы не может быть измерено с помощью тщательно сконструированного теста, то в таком случае, эти признаки не поддаются также измерению ни в эссе, ни в сочинениях, ни с помощью 
прочих традиционных форм проверки, что противоречит истине.

Исследователь А. Н. Кирейцева отмечает, что противниками использования в тестах заданий открытой формы обычно выступают именно тестологи, не связанные с гуманитарными науками (2013: 51). Этот факт объясняется тем, что в таких заданиях готовые ответы не даются, их должен продуцировать сам испытуемый, выбирая правильный вариант из множества собственных знаний, что противоречит самой сущности точных наук.

Действительно, разница во взглядах на тестирование определяется различием между гуманитарными науками, с одной стороны, и точными и естественными - с другой. Очевидно, что «различия между естественно-научным и гуманитарным знанием существуют объективно и связаны с объектом, субъектом и методами исследования» (Горбухова, 2007: 101). Следовательно, структурное несовпадение самих наук, методических приёмов и подходов в обучении соответствующим дисциплинам влекут за собой и различия в используемых тестовых материалах. И в первую очередь это касается заданий открытого типа со свободно конструируемым ответом, которые не применяются в тестах по математике, физике, астрономии, химии и др. (Аванесов, 2002, 2006; Кирейцева, 2013; Челышкова, 2002, и др.), но без которых не обходится ни одно испытание по филологическим дисциплинам, истории и др. (Devies, 1968; Oller, 1980; Балыхина, 2006; Коккота, 1989; Лазарева, 2011; Переверзев, 2003; Рапопорт, 1987, и др.), поскольку умение продуцировать письменный и/или устный речевой продукт является неотъемлемой частью профессиональной подготовки гуманитария. Более того, наличие в тестах по гуманитарным дисциплинам заданий со свободно конструируемым ответом оправдано новейшими методами создания интерпретационной базы для их оценки, поскольку «всё, что существует в природе, существует в определённом количестве, а всё, что существует в определённом количестве, может быть измерено» (Цатурова, 2001: 27). Начало таким измерениям положили тесты на измерение IQ в психологии. ETS, мировой лидер в индустрии создания и разработки тестов, включает в тесты TOEFL ${ }^{1}$, IELTS ${ }^{2}$ и др. субтесты, требующие продуцируемой устной речи (Speaking-Test) и письменной речи (Writing-Test). Ответы на такие тестовые задания открытой формы со свободно конструируемым ответом проверяются по научно разработанным интерпретационным таблицам. Таким образом, проблема включения или невключения заданий открытого типа в тестовые материалы связана с трудностями объективного измерения результатов их выполнения, определения числового показателя в их оценке, т.е. их стандартизации и создании интерпретационной базы. Однако, с нашей точки зрения, «трудно» - это не означает «невозможно» (см. Кирейцева, 2004; Цатурова, 2001, и др.). По нашему мнению, использование

1 Например, http://www.ets.org/s/toefl/pdf/toefl_writing_rubrics.pdf

2 Например, http://www.ielts.org/test_takers_information/test_sample.aspx 
таких заданий в тестах по гуманитарным дисциплинам тем более актуально в свете современных положений (в новой европейской стратегии экономического развития «Europa 2020» ${ }^{3}$, в программе «Švietimas ir mokymas 2020» ${ }^{4}$ и др. подчёркивается, что в учебные программы необходимо включать развитие навыков творчества и изобретательности у учащихся, а также выявлять эти навыки при помощи различных средств). Данное обстоятельство послужило дополнительным аргументом в пользу внедрения в процесс контроля учителей РКИ (в качестве задания открытого типа со свободно конструируемым ответом) написание конспекта урока, требующего от испытуемого, безусловно, творческого подхода.

Таким образом, суть проблемы «заданий открытого типа» в тесте, с нашей точки зрения, связана лишь с трудностями их стандартизации и создания интерпретационной базы, являющейся необходимым условием любого тестового задания. Однако данное затруднение не кажется нам непреодолимым. Мы считаем, что эссе, сочинения, письменные и устные ответы по экзаменационным билетам и прочий контроль, требующий продуцированной речи, не может считаться тестовым заданием только в случае, если не имеет научно обоснованной и апробированной измерительной таблицы для интерпретации ответа. Тогда такое задание превращается в учебное и преследует цель, например, в случае с иностранным языком, формирования навыков и умений устной или письменной речи. Соответственно, вопрос о включении или невключении в тесты заданий открытого типа зависит от процедуры их стандартизации и наличия доказательной интерпретационной базы.

Мы полагаем, что в системе контроля будущих учителей РКИ в качестве тестового задания открытого типа со свободно конструируемым ответом логично предложить студентам написание конспекта урока на заданную методическую тему. Как было определено выше, данная форма контроля требует разработки апробированного шаблона для объективного оценивания.

Необходимость создания конспекта урока является одной из составляющих профессиональной деятельности учителя-филолога, ведь «даже гении, создававшие шедевры, прежде всего создают гениальный план, продумывают, многократно перерабатывают в уме детали произведения искусства, в том числе и для урока» (Зотов, 1984: 113). Также никем не оспаривается и необходимость обучения студентов-филологов разработке конспекта урока как речевого произведения, что подтверждается предусмотренными для этой цели часами в содержании курса дисциплины «Дидактика преподавания РКИ» при подготовке специалистов и в Литве, и в России 5 . Во время прохождения педа-

\footnotetext{
3 Cм. http://ec.europa.eu/europe2020/index_en.htm

4 См. http://ec.europa.eu/education/lifelong-learning-policy/doc28_en.htm

5 Эксперименты по внедрению в педагогический контроль тестовых заданий открытого типа проходили на кафедрах русского языка в Литовском эдукологическом университете (ЛЭУ), Вильнюсском университете (ВУ), Санкт-Петербургском государственном университете (СПбГУ), Российском государственном педагогическом университете им. А. И. Герцена (РГПУ) и Невском институте языка и культуры (НИЯК).
} 
гогической практики учащиеся также должны разрабатывать конспекты планируемых уроков, что бесспорно позволяет облегчить и ускорить сложный процесс профессионального становления будущего учителя. По окончании педагогической практики все студенты в обязательном порядке должны предоставить конспекты урока для оценки руководителю этой практики.

Тем не менее, приходится констатировать тот факт, что при предусмотренных обязательных занятиях по обучению создания конспекта урока и планированном его оценивании не существует чётких критериев контроля этой работы, по крайней мере, нам не удалось их обнаружить ни в научно-методической литературе, ни в соответствующих документах указанных кафедр, готовящих учителей РКИ. Конспект урока проверяется преподавателем лишь с точки зрения его собственных предпочтений и опыта, что представляется крайне субъективным. Повысить уровень объективности проверки можно, составив на основе мнений специалистов в данной области измерительную таблицу, и в соответствии с ней оценивать тот или иной «письменный опус». В таком случае конспект оценивается без опоры на предпочтение и опыт преподавателя (поскольку очевидно, что предпочтения и опыт у всех разный).

В этой связи на основе мнений многочисленных компетентных экспертов $^{6}$, высказавшихся по поводу обязательных критериев, которые должны подвергаться оцениванию, несущественных позиций, факультативно присутствующих в конспекте урока, и дополнительных параметров, поощряемых плюсбаллами, нами была разработана измерительная таблица с перечисленными оцениваемыми характеристиками и требованиями к разработке конспекта урока. Таким образом в таблице были определены обязательные позиции - содержание, последовательность, методы и приёмы обучения, основные дидактические средства и другие прописанные позиции, за которые, в зависимости от наличия или отсутствия указанной информации, начисляются или удерживаются баллы. Также необходимо учитывать, что продуцируемый ответ может содержать элементы, не отражённые в измерительной таблице. Для уместного выхода за рамки обязательных требований к "классическому уроку" (например, продемонстрированный творческий подход к уроку, использование альтернативных методов преподавания и проч.) предусматривается присвоение испытуемому дополнительных баллов. Отдельным критерием выносится и оценка грамотности выполненной работы.

При проверке конспекта урока преподаватель фиксирует по измерительной таблице методическую адекватность студенческого ответа, а также речевые параметры и качества письменной речи. При этом студент в ходе написания конспекта урока как речевого произведения должен продемонстрировать, во-первых, владение материалом по преподаваемому предмету, во-вторых, умение эффективно решать педагогические задачи при реализации учебной

6 В эксперименте принимали участие 27 экспертов пяти указанных петербургских и вильнюсских вузов со стажем преподавания дисциплины «Дидактика преподавания РКИ» не менее 10 лет. 
программы. В-третьих, конспект должен быть написан в виде профессионального полилога учителя с учениками в соответствии с нормами современного русского литературного языка, что позволяет судить и об уровне речевой культуры будущего педагога и, как следствие, о его профессиональной подготовленности. Таким образом, разработанная измерительная таблица для контроля конспекта урока по всем перечисленным позициям стандартизирует свободно конструируемые ответы учащихся и объективизирует оценку выполненного задания. Только в этом случае такое задание может называться тестовым заданием открытого типа со свободно конструируемым ответом.

В течение пяти лет ${ }^{7}$ составленная таблица была испытана более чем на 1400 конспектах уроков, написанных учащимися ЛЭУ, ВУ, СПбГУ, РГПУ и НИЯК. В первые три года по таблице была исследована тысяча ранее созданных студентами и оценённых преподавателями конспектов. Во время анализа выставленная преподавателем оценка сравнивалась с результатом, полученным по разработанной измерительной таблице. В конечном итоге были конкретизированы оцениваемые параметры и определены критерии оценки, согласованные с ранее задействованными экспертами, в результате чего, таблица была усовершенствована и затем успешно апробирована на более чем 400 письменных работах студентов указанных вузов в непосредственном процессе университетской подготовки ${ }^{8}$ и педагогической практики ${ }^{9}$. Проведённые процедуры гарантировали обоснованность окончательного аттестационного решения. При этом созданные студентами конспекты урока подвергались двойной проверке (оценивались ведущим преподавателем и исследовались при помощи измерительной таблицы), затем полученные баллы сравнивались. Результаты расчётов показали высокое взаимосоответствие оценок (более $80 \%$ ). Полученные данные свидетельствуют о достаточной достоверности разработанной измерительной таблицы. Однако нельзя не отметить и некоторые случаи несовпадения баллов. Мы объясняем этот факт не только известной долей субъективизма самой проверки работ преподавателями, но также их разным педагогическим опытом. Заметные расхождения в баллах были обнаружены в случае проверки работ молодыми преподавателями со стажем не более четырёх лет, что говорит о необходимости использовать в их практике измерительную таблицу для приобретения навыка объективного оценивания студенческих конспектов урока.

Внедрение данного вида проверки письменной работы в схему контроля бакалавров 4 курса ЛЭУ было проведено на итоговом испытании по дисциплине «Дидактика преподавания РКИ». ${ }^{10}$ Следует отметить, что при данном контроле критических несовпадений с предполагаемыми оценками выявлено

\footnotetext{
7 Период $2010-2014$ гг.

8 Студенты РКИ 3 и 4 курсов ЛЭУ, СПбГУ, РГПУ, 4 курса ВУ, а также студенты НИЯК (2012 - 2014 уч. г.).

9 Студенты РКИ 4 курса ЛЭУ, ВУ, СПбГУ, а также студенты НИЯК (2012 - 2014 уч. г.).

10 Летняя сессия 2013-2014 уч. гг.
} 
не было: оценки оправдали ожидание и преподавателя, и самих студентов, а во время процедуры контроля все участники процесса ощущали себя комфортно, что выяснилось при последующем анонимном анкетировании. ${ }^{11}$ Полученные при многократных экспериментальных проверках результаты, проведённые подсчёты и успешное внедрение разработанной измерительной таблицы для оценивания конспекта урока доказывают, что предложенная тестовая форма задания способствует эффективному и объективному контролю.

\section{Выводы}

Таким образом, в настоящей статье для объективного контроля квалификационной пригодности будущих учителей РКИ предлагается использовать экспериментально проверенную в условиях вузовской подготовки и педагогической предметной практики измерительную таблицу оценивания конспектов уроков, разработанных студентами по специальности РКИ. При этом валидность измерительной таблицы обоснована экспертным методом, а надёжность подтверждается в ходе многочисленных экспериментов с привлечением в общей сложности более 1400 работ студентов пяти вузов двух стран. Полученные результаты убеждают нас в том, что только научно разработанная, стандартизированная и апробированная измерительная таблица является единственным объективным методом контроля подобной письменной работы студента, а написание конспекта урока в данном случае правомерно можно назвать выполнением тестового задания со свободно конструируемым ответом. Мы считаем, что лишь научно сконструированный контрольный тестовый материал позволит объективно измерить реальные знания и умения испытуемых, достоверно оценить качество обученности будущего учителя и тем самым повысить эффективность процесса обучения в целом.

\section{Литература}

1. Choppin, B. N.; Purves, A. C. (1969) A Comparison of Open-ended and Multiple-choice Items Dealing with Literary Understanding. Research in the Teaching of English, 3: 15-24.

2. Devies, A. (1968) Language Testing Symposium. A Psycholinguistic Perspective. London: Oxford University Press.

3. Educational Testing Service Center (USA) [žiūrèta 2016-02-20]. Prieiga per internetą: http://www.ets.org/

4. Haristan, A. (1971) The Effect of Study Methods and Test Performance of Objective and Essay Examinational. Journal of Educational Research, 64(8): 324.

5. International English Language Testing System [žiūrèta 2016-02-20].

11 В анонимном анкетировании все испытуемые имели возможность высказаться по поводу полученной оценки и своих впечатлений от пройденного тестирования. 
Prieiga per internetą: http://www.ielts.org/

6. Oller, J. W. (1980) Research in Language Testing. Rowleyn (Mass.): Newbury House.

7. Programa «Švietimas ir mokymas 2020» [žiūrèta 2014-10-09] Prieiga per internetą: http://ec.europa.eu/education/lifelong-learning-policy/doc28_en.htm.

8. Strategija «Europa 2020» [žiūrèta 2016-02-20]. Prieiga per internetą: http://ec.europa.eu/europe2020/index_en.htm

9. Аванесов, В. С. (2002) Композиция тестовых заданий. Москва: Ассоциация инженеров-педагогов г. Москвы.

10. Аванесов, В.С. (2006) Форма тестовых заданий. Москва: Изд-во Центр тестирования.

11. Балыхина, Т. М. (2006) Словарь терминов и понятий тестологии. Москва: Изд-во Русский язык, Курсы.

12. Горбухова, М. Ю. (2007) Естествознание и гуманитарные науки: различие и проблема единства в контексте формирования гуманитарной культуры специалиста-естествоиспытателя. Известия Алтайского государственного университета, №2: 101-105.

13. Зотов, Ю. Б. (2984) Организация современного урока. Москва: Изд-во Просвещение.

14. Ингенкамп, К. (1991) Педагогическая диагностика / Перевод с нем. Москва: Изд-во Педагогика.

15. Кирейцева, А. Н. (2013) Азбука тестирования. СПб: Изд-во Златоуст.

16. Кирейцева, А. Н. (2004) Как объективно проверить сочинение? Материаль ХХХІІІ Международной филологической конференичи. №16: 232243.

17. Коккота, В. А. (1989) Лингводидактическое тестирование. Москва: Изд-во Высшая школа.

18. Лазарева, О. А. (2011) Школа тестора: лингводидактическое тестирование ТРКИ-TORFL. СПб.: Изд-во Осипова.

19. Переверзев, В. Ю. (2003) Критериально-ориентированное педагогическое тестирование. Москва: Изд-во Логос.

20. Рапопорт, И. А.; Сельг, Р.; Соттер, И. (1987) Тесты в обучении иностранным языкам в средней школе. Таллин: Изд-во Валгус.

21. Цатурова, И. А. (2001) Тестирование устной коммуникации. Таганрог: Изд-во Высшая школа.

22. Челышкова, М. Б. (2002) Теория и практика конструирования педагогических тестов. Москва: Изд-во Логос. 


\title{
LESSON SUMMARY AS AN OPEN-ENDED TEST ITEM WITH A FREE-RESPONSE ANSWER
}

\author{
Dr. Julia Sutuginienè \\ Emperor Alexander I Petersburg State Transport University
}

Summary. Nowadays, the question of the use of an open-ended test item is undeservedly left out of the field of vision of the pedagogical association. The author of the article explains this fact on the basis of different views on testing among the researchers in humanitarian arts from one point of view and in the exact or natural sciences from the other point of view. It is stated that the point of the problem of an open-ended test item is connected only with the difficulties of their standardization and creation of the basis for interpretation, which is a necessary condition for any test item.

The author thinks that it is quite possible. Thus, this article theoretically shows the necessity of working out an open-ended test item as well as the table of measurement for its evaluation. Besides, the author experimentally proves the advisability to include these types of test items into control for the objective measurement of professional skills of students as future Russian as a Foreign Language (RFL) teachers. As an open-ended test item, it has taken the preparation of the summary of a lesson written by students for its investigation it is necessary to create the table of measurement.

As the author thinks, only scientifically prepared, standardized and probated table of measurements is the only unbiased control method of a student's written work, therefore, a lesson summary in such a case is rightfully called a test item fulfilment. In connection with this, using the method of expert assessments, the author worked out the table of measurements in which the requirements for the lesson summary were enumerated as well as the estimated characteristics were listed. The experiments on preparation, approbation and implementation of test material in the pedagogical control, described in the article, were done during five years in Lithuania and Russia on the basis of the Departments of Russian Language at the LUES, VU, SPSU, HSPUR, NILC where future teachers of RFL get their Bachelor's degree. Thus, the reliability and validity of the offered test item was proved. 


\section{AUTORIAUS LYDRAŠTIS}

Autoriaus vardas, pavardè: Julija Sutuginienè

Mokslo laipsnis ir vardas: socialinių mokslų daktarè, edukologija (07 S)

Darbo vieta ir pareigos: Peterburgo valstybinio imperatoriaus Aleksandro I susisiekimo kelių universiteto Rusų kalbos katedros lektorè (Sankt Peterburgas, Rusija)

Autoriaus mokslinių interesų sritys: rusų kalbos kaip užsienio dėstymo metodika, lingvodidaktinio ir pedagoginio testavimo teorijos ir praktikos klausimai

Telefonas ir el. pašto adresas: +79219723488; sutuginiene@mail.ru

\section{AUTHOR'S COVER LETTER}

Author's name and surname: Julia Sutuginienè

Academic degree and name: Doctor of Social Sciences, Educational Sciences (07 S) Workplace and position: Emperor Alexander I Petersburg State Transport University, Department of Russian Language, Senior Lecturer

Author's research interests: didactics of teaching RFL, theoretical and practical problems of linguistic and pedagogical testing

Telephone and e-mail address: +79 219723 488; sutuginiene@mail.ru 